\title{
Evaluation of a community- based clinical teaching programme by current and former student dental therapists and dental hygienists: a pilot investigation
}

\author{
C. D. Lynch, ${ }^{1}$ P. J. Ash ${ }^{2}$ and B. L. Chadwick ${ }^{3}$
}

\section{VERIFIABLE CPD PAPER}

Aim There has been considerable expansion in the involvement of community-based clinical teaching programmes (sometimes termed 'outreach teaching') in UK and other international dental schools. While there has been much interest in the role of this educational methodology in the professional and educational development of student dentists, there has been little, if no, consideration of this form of teaching in relation to dental care professional (DCP) students. The aim of this pilot investigation was to report the feedback and evaluation of current and former student dental therapists and dental hygienists on their experience on the St David's community-based clinical teaching programme at Cardiff. Methods In Autumn 2009, a questionnaire was distributed by hand to the current second year student dental therapist and dental hygiene class at Cardiff $(n=18)$ and by post to the dental therapist and dental hygiene classes of $2004(n=16)$ and 2007 $(n=17)$. The questionnaire included both 'open' and 'closed' questions. Results Thirty responses were returned (response rate $=59 \% ; 2004(n=5,31 \%), 2007(n=9,53 \%)$, current class $(n=16,89 \%))$. Seventy percent of respondents $(n=21)$ reported that they found the community-based clinical teaching programme to be a pleasant working environment and close to subsequent independent practice. Seventy-seven percent $(n=23)$ reported that their confidence performing nonsurgical periodontal treatment had increased while at the programme. One respondent commented that the programme was '... an invaluable and insightful introduction to what it would be like working in practice. Without being given the experience, it would have been a big shock to the system when I started working in practice...' Conclusion This pilot investigation has revealed that current and former dental therapist and dental hygiene students are enthusiastic in their support for the inclusion of community-based clinical teaching programmes in their educational and professional development. Most former and current dental therapist and dental hygiene students noted the positive effects of this form of training on their subsequent clinical careers.

\section{INTRODUCTION}

In recent years, the concept of the dental team has become more established within the dental profession, and is regarded as being in the best interests of patients. ${ }^{1}$ Two classes of dental care professionals (DCPs) on which increasing responsibilities are

*Senior Lecturer/Honorary Consultant in Restorative Dentistry, Tissue Engineering \& Reparative Dentistry, ${ }^{3}$ Professor/Honorary Consultant in Paediatric Dentistry, School of Dentistry, Cardiff University, Cardiff, CF14 $4 \mathrm{XY} ;{ }^{2}$ Consultant/Director of Primary Dental Care Outreach Units, St David's Primary Dental Care Unit, St David's Hospital, Cardiff

*Correspondence to: Dr Christopher D. Lynch Email: Iynchcd@cardiff.ac.uk

\section{Refereed Paper}

Accepted 7 April 2011

DOI: 10.1038/sj.bdj.2011.384

British Dental Journal 2011; 210: 481-485 placed are dental hygienists and dental therapists. Dental hygienists have been employed within UK general dental practices for many years, and the scope of their duties are associated with the delivery of periodontal and preventive care. More specifically, under the prescription of a registered dentist, they may perform nonsurgical periodontal treatment, administer local anaesthesia and provide oral hygiene instruction. In more recent years, there has expansion in the role, scope of practice and numbers of dental therapists involved in the delivery of dental care within the United Kingdom. ${ }^{2}$ Following guidance from the General Dental Council (GDC) and owing to the structure of DCP training programmes, dental therapists trained within the UK are effectively duallyqualified dental hygienist-therapists. ${ }^{3}$ As such, the range of clinical procedures that registered dental therapists may perform under prescription from a registered dentist include periodontal care, preventive dentistry, extraction of primary teeth, impression-making, and placement of simple (no pulpal involvement) direct restorations, among others. ${ }^{4}$ Since 2002, dental therapists can work in all sectors of dentistry, including general dental practice. ${ }^{5,6}$ According to recent figures supplied by the GDC, 5,631 dental hygienists and 1,471 dental therapists are listed on the DCP register. ${ }^{7}$ The development in numbers and in scope of practice of dental hygienists and dental therapists has also followed 
from the publication of Options for change and the policies of the NHS Modernisation Agency. ${ }^{2,8}$ Primary-care based studies have indicated that a significant proportion of treatments undertaken in general dental practices could be delegated to DCPs, allowing dentists to provide other, more advanced treatments, thereby increasing access to dental care for patients. ${ }^{9}$

At the same time, there have been considerable innovations in student dentist education, an important example of which is the incorporation of community-based clinical teaching programmes (sometimes termed 'outreach teaching') into traditional dental school curricula. Community-based clinical teaching programmes offer many advantages to contemporary, traditional, dental school programmes, including opportunities to provide holistic dental care for patients in a primary care setting, development of practice management skills and working as part of a dental team, among others. ${ }^{9}$ While there are international examples of successful community-based clinical teaching programmes, such as those in North America ${ }^{11-13}$ and Australia, ${ }^{14}$ there are also notable examples of successful UK-based programmes. Some of these developed in relation to specific disciplines such as paediatric dentistry or restorative dentistry. ${ }^{15,16}$ Recently UK dental schools have begun to develop community-based clinical teaching programmes which are based on either a 'dispersedpractice' model such as the Sheffield programme, ${ }^{17}$ or in purpose-built units such as those at Leeds, ${ }^{18}$ King's College London, ${ }^{19}$ or own centre at Cardiff. ${ }^{20}$ The Cardiff programme commenced at the St David's Hospital in 2002. This community-based clinical teaching programme was sited in an area of high-population density with significant need of treatment for 'new' dental disease (such as primary lesions of caries, periodontal disease, etc). The clinic is located close to Cardiff city centre, and attending patients are from a multi-ethnic population across a wide age profile. The St David's clinic has 12 chairs, with each teaching session typically including 10 dental student operators - each assisted by a qualified dental nurse - and two DCP students (usually dental hygiene or dental therapy students) operating in the same clinic simultaneously. Within this environment, the developing dental team allows for sharing of patients, delegation of patients from student dentists to student dental therapists and dental hygienists, where appropriate, and close liaison on patient management. For many sessions, the same supervisor attends to student dentists and student dental therapists and dental hygienists, further illustrating a common approach to student education. Contemporaneous feedback from student dentists and their self-reported improvement in confidence in performing certain clinical tasks as a result of their experience at this centre has been very positive. ${ }^{21}$ In addition, recent feedback from our graduated dental students indicates that their educational experience at the St David's community-based clinical teaching programme had an important positive impact on their subsequent clinical careers as independent practitioners. ${ }^{22}$

However, very little, if any, information exists on the impact of community-based clinical teaching programmes on the clinical and professional development of dental hygienists and dental therapists. The aim of this pilot investigation was to report the feedback and evaluation of current and former dental therapist and dental hygiene students on their experience on the St David's community-based clinical teaching programme at Cardiff.

\section{MATERIALS AND METHODS}

In Autumn 2009, a pre-piloted questionnaire was distributed by hand to the current second year DCP student class at Cardiff ( $n=18$ ) and by post to the graduating dental therapy and dental hygiene classes of $2004(\mathrm{n}=16)$ and $2007(\mathrm{n}=17)$. The questionnaire included both 'open' and 'closed' questions. These questions were informed by questions used in previous surveys of dental students and graduated dentists..$^{21,22}$ Information sought in this questionnaire included:

- What the respondents liked about their educational experience at the community-based clinical teaching programme

- What the respondents disliked about their educational experience at the community-based clinical teaching programme

- How the respondents felt that their clinical confidence in performing certain clinical techniques improved due to their educational experience at the community-based clinical teaching programme

- How the respondents compared their educational experience at the community-based clinical teaching programme with that at the base dental school.

The questionnaires to the current students were distributed to students at the end of an academic year. It was explained that responses were optional and there was no 'follow-up' of non-responders. For questionnaires sent by post to graduated dental therapists and dental hygienists, a stamped addressed envelope was included for return of questionnaires that were distributed by post. Each posted questionnaire was tracked using a confidential code. Non-respondents were followed up with a further questionnaire after six weeks.

The supplied cover letter for all groups indicated that participation in this programme evaluation was voluntary. Data were entered anonymously onto an electronic database. Descriptive statistics are reported.

\section{RESULTS}

Thirty completed responses were returned (response rate $=59 \%$ ). When considered by individual group:

- Class of 2004: featured a 31\% response rate with five responses from a possible 16 former students contacted. Four of these responses came from the first mailing and one from the second mailing

- Class of 2007: featured a 53\% response rate with nine responses from a possible 17 former students contacted. Six of these responses came from the first mailing and three from the second mailing

- Current dental therapy and dental hygiene students: featured an 89\% response rate with 16 responses from a possible 18 students.

Former and current student 'likes' are reported in Table 1. The most commonly reported 'like' among all respondents related to their perception that the community based teaching programme mimicked their actual or anticipated experience once qualified and working 
Table 1 Common 'likes' reported by former and current DCP students in relation to the community-based clinical teaching programme

\begin{tabular}{|l|l|l|l|l}
\hline & $\begin{array}{l}2004 \text { class } \\
(n=5)\end{array}$ & $\begin{array}{l}2007 \text { class } \\
(n=9)\end{array}$ & $\begin{array}{l}\text { Current class } \\
(n=16)\end{array}$ & Total $(n=30)$ \\
\hline $\begin{array}{l}\text { Pleasant working environment/ } \\
\text { close to subsequent } \\
\text { independent practice }\end{array}$ & 5 & 6 & 10 & 21 \\
\hline $\begin{array}{l}\text { Growing sense of confidence/ } \\
\text { independence }\end{array}$ & 1 & 4 & 8 & 13 \\
\hline Modern clinic/equipment & 1 & 3 & 5 & 8 \\
\hline Good patient mix & 1 & 2 & 4 & 7 \\
\hline Computerised patient records & 0 & 2 & 4 & 6 \\
\hline Teaching staff/method & 0 & 2 & 2 & 4
\end{tabular}

Table 2 Common 'dislikes' reported by former and current DCP students in relation to the community-based clinical teaching programme

\begin{tabular}{l|l|l|l|l}
\hline 'Dislikes' & $\begin{array}{l}2004 \text { class } \\
(n=5)\end{array}$ & $\begin{array}{l}2007 \text { class } \\
(n=9)\end{array}$ & $\begin{array}{l}\text { Current class } \\
(n=16)\end{array}$ & Total $(n=30)$ \\
\hline $\begin{array}{l}\text { Problems with computerised } \\
\text { record system }\end{array}$ & 2 & 2 & 5 & 9 \\
\hline $\begin{array}{l}\text { Difficulties associated with } \\
\text { nursing support }\end{array}$ & 1 & 1 & 6 & 8 \\
\hline $\begin{array}{l}\text { Logistical issues travelling } \\
\text { between base dental hospital } \\
\text { and St David's Hospital }\end{array}$ & 0 & 2 & 3 & 5 \\
\hline $\begin{array}{l}\text { Lack of specialised periodontal } \\
\text { equipment (eg long ultrasonic } \\
\text { scaler tips) }\end{array}$ & 0 & 0 & 4 & 4
\end{tabular}

Table 3 Numbers of students reporting an improved confidence in performing a selection of clinical tasks following experience on the community-based clinical teaching programme

\begin{tabular}{|l|l|l|l|l} 
Clinical technique & $\begin{array}{l}2004 \text { class } \\
(n=5)\end{array}$ & $\begin{array}{l}2007 \text { class } \\
(n=9)\end{array}$ & $\begin{array}{l}\text { Current class } \\
(n=16)\end{array}$ & Total $(n=30)$ \\
\hline Performing scaling & 5 & 8 & 10 & 23 \\
\hline Administering local anaesthesia & 5 & 9 & 3 & 17 \\
\hline Working as part of a dental team & 2 & 6 & 7 & 15 \\
\hline Working with a dental nurse & 2 & 4 & 1 & 7
\end{tabular}

Table 4 Comparisons between the community-based clinical teaching programme and the base dental hospital reported by current and former DCP students

\begin{tabular}{|l|l|l|l|l}
\hline Clinical technique & $\begin{array}{l}2004 \text { class } \\
(n=5)\end{array}$ & $\begin{array}{l}2007 \text { class } \\
(n=9)\end{array}$ & $\begin{array}{l}\text { Current class } \\
(n=16)\end{array}$ & Total $(n=30)$ \\
\hline More like independent practice & 4 & 1 & 8 & 13 \\
\hline $\begin{array}{l}\text { Better range of patients/better } \\
\text { attendance pattern }\end{array}$ & 1 & 0 & 11 & 12 \\
\hline Better teaching ratio & 0 & 5 & 5 & 10 \\
\hline More freedom to make decisions & 0 & 4 & 6 & 10 \\
\hline Increased sense of confidence & 0 & 4 & 5 & 9 \\
\hline More 'relaxed' environment & 1 & 3 & 3 & 7
\end{tabular}

in independent practice ( $\mathrm{n}=21,70 \%$ ). 'Dislikes' are reported in Table 2. The most common 'dislike' related to problems associated with the use of computerised records ( $\mathrm{n}=9,30 \%$ ). Respondents reported on how they felt their confidence increased in performing a range of clinical tasks following their experience on the community-based clinical teaching programme (Table 3). Seventy-seven percent $(n=23)$ reported that their confidence performing scaling had increased following their experience, and 57\% ( $\mathrm{n}=17$ ) reported that their confidence administering local anaesthesia had increased.

Forty-three percent $(n=13)$ considered the community-based clinical practice preferable to the base dental school because they felt it was more representative of what they would experience/had experienced in subsequent independent practice, while 40\% ( $n=12$ ) noted that the range of patients and patient attendance patterns were considered better than that encountered at the base dental hospital (Table 4).

A representative sample of some general comments reported by respondents in relation to the community-based clinical teaching programme are reported in Table 5. One such respondent noted '...I feel that as I have progressed in St David's my confidence has greatly improved due to increased independence and being allowed to make own decisions clinically...'

\section{DISCUSSION}

The 'team approach' to the delivery of dental care - led by a registered dentist who diagnoses dental disease, prescribes a course of treatment and delegates the delivery of more 'routine' treatments - is now established within UK dentistry. ${ }^{23,24}$ Some of the obvious advantages in this approach include the optimisation of patient care, with a single patient being exposed to the abilities and skills of a number of healthcare practitioners, the delivery of so-called 'routine' treatments by those who are exclusively trained in these areas, and the 'freeing up' of dentists, who by benefit of their training have a broader skills-mix, to provide more 'advanced' treatments such as prosthodontics and endodontics. This latter point has received recent emphasis where access to care for certain endodontic and prosthodontic treatments within general dental practice has been shown to be problematic. ${ }^{26-28}$

However, notwithstanding the clear advantages of the dental team, primarycare based studies have highlighted that the 'team approach' is under-utilised within UK practices. ${ }^{5,9}$ A recent study carried out in Wales illustrated that almost $60 \%$ of clinical time was expended by dentists on treatments that fell within the scope of practice of, and could have been delegated to, dental therapists and dental 
hygienists. ${ }^{9}$ While the authors speculated that one possible cause for this lack of utilisation of dental therapists and dental hygienists related to financial concerns, another possible reason could relate to a lack of understanding on the part of dentists in relation to the role of dental therapists and dental hygienists, which has been previously highlighted elsewhere. ${ }^{5} \mathrm{~A}$ real opportunity for overcoming this barrier of a lack of knowledge of the roles of dental therapists and dental hygienists exists within current dental school training programmes for both dental students and student dental therapists and dental hygienists. The GDC's guidance document on dental student education (The first five years) highlights the benefits of dental students training as part of a dental team and comments on the importance of dental team working, with opportunities for student dentists to train and work with other dental professionals.28 This recommendation is included in the GDC guidance document on DCP education (Developing the dental team), which additionally comments that 'the newly qualified DCP must have ... an ability to work effectively as a member of the dental team: ${ }^{29}$ The benefits of incorporating an integrated approach has also been highlighted in a recent study of dental student education..$^{30}$ With such an emphasis on the importance of developing dental teams within educational/dental schools environments, the St David's model exploits the opportunity of dental team development and will help overcome barriers to the employment of dental therapists and dental hygienists within dental practices in the future. The St David's clinic has student dentists and student dental therapists and dental hygienists operating within the same unit simultaneously. Within this environment, the developing dental team allows for sharing of patients, delegation of patient care from student dentists to student dental therapists and dental hygienists, where appropriate, and close liaison on patient management. For many sessions, the same supervisor attends to student dentists and student dental therapists and dental hygienists, further illustrating a common approach to student education. The benefits of this approach is highlighted in the growing confidence of student dental therapists and dental hygienists in working as part of a

Table 5 A representative sample of comments received from respondents on what they felt were the positive attributes of the community-based clinical teaching programme

Comments by respondents in relation to positive attributes of training programme

Relaxed atmosphere, St David's offered a chance to gain confidence and an insight into general practice...'

better than hospital as more realistic to practice after qualification...

...it was an invaluable and insightful introduction to what it would be like working in practice. Without being given the experience, it would have been a big shock to the system when I started working in practice...

'Atmosphere is much more realistic to work in, gives much more insight into working in practice. Units are much smaller and more organised...'

'... I feel that as I have progressed in St David's my confidence has greatly improved due to increased independence and being allowed to make own decisions clinically...

...The patients I see here are more applicable to what you will see in practice, whereas in the dental hospital, you see the more 'extreme' cases. I see a lot more ethnic groups here...'

the teaching staff value our opinions and treatment choices...

dental team (Table 3), with a similar sense of growing confidence in team-working noted previously among Cardiff dental students. ${ }^{22}$ Given the desirability for student education to be completed in environments which will closely mimic subsequent arrangements in independent practice, ${ }^{10}$ this approach for development of student dentists and student dental therapists and dental hygienists within a communitybased clinical teaching environment is to be welcomed.

Apart from the aspect of team-building, it is also of note that within the sample surveyed, there was an increase in confidence in performing so-called 'routine' clinical tasks among dental therapists and dental hygienists, with 77\% reporting increased confidence when performing periodontal treatments and 57\% reporting a similar increased confidence when administering local anaesthesia. A previous paper has demonstrated that dental student confidence increased when performing 35 out of 36 clinical tasks within a communitybased clinical teaching environment. ${ }^{21}$ In contrast to other centres, the Cardiff/St David's community-based clinical teaching model permits students to provide 'total patient care' for their patients including both children and adults - within a primary-care setting rather than focusing on discrete clinical specialties such as restorative or paediatric dentistry. The free-text comments from respondents also provide insight into the views of current and former students, with one respondent noting '...I feel that as I have progressed in St David's my confidence has greatly improved due to increased independence and being allowed to make own decisions clinically...' (Table 5). Such comments underline the value and importance of community-based clinical teaching for the professional development of student dental therapists and dental hygienists. To the best of our knowledge no previous UK, or indeed international, studies have investigated the value of this form of educational development for DCPs, including dental therapists and dental hygienists.

While many of the areas of growing confidence and 'likes' noted among dental therapists and dental hygienists respondents were similar to those noted in previous surveys of dental students and graduated dentists, ${ }^{20,22}$ an aspect of divergence between the dental students group dental therapists and dental hygienists group related to working with a dental nurse. While current and former dental students were exceedingly positive in relation to their growing confidence when working with dental nurses following their time at the St David's unit, ${ }^{20,22}$ respondents to the student dental therapist and dental hygienist survey did not seem to share the same enthusiasm - less than $25 \%$ of student dental therapists and dental hygienists noted increased confidence in working with dental nurses (Table 3). This finding is of concern to the authors, and suggests that graduating dental therapists and dental hygienists are not as confident in working with dental nurses as they could be. This could be a reflection of funding issues within the St David's Unit - while there is dental nursing support for each dental student, this is not always the case for student dental therapists and dental hygienists. Student dental therapists and dental hygienists occasionally work 
single-handed, or else assisting each other. On some occasions it is possible to provide dental nursing support to student dental therapists and dental hygienists. Clearly, issues like this have the potential to undermine team working and should be considered carefully at the planning stage to optimise the student dental therapist and dental hygienist experience.

As with any questionnaire-based study, there are certain inherent risks when interpreting findings. Questionnaire-based studies offer a number of advantages including data collection over a larger area, with relative ease and lower costs compared to other methods such as interviewing. ${ }^{31}$ Questionnaires reduce the risk of interview bias by allowing respondents to answer questions in privacy in the absence of an interviewer. ${ }^{32}$ On the other hand, the response rate for this survey was 59\%, leading to a possible claim of responder bias, ie those who are more enthusiastic about this subject chose to respond..$^{33}$ The response rate noted in this study (59\%) was slightly less than the suggested acceptable response rate to questionnaires (64\%), ${ }^{34}$ but greater than those from other recentlypublished studies on diverse topics such as dental nurse education (53\%), ${ }^{35}$ rubber dam usage $(50 \%)^{27}$ and local anaesthetic teaching programmes (18\%). ${ }^{36}$ In any case, the purpose of this present study was to present pilot data and further investigation of the relevance of community-based clinical teaching to the educational and professional development of student dental therapists and dental hygienists along with the development of dental teams is indicated, possibly via formalised focus group methodologies.

\section{CONCLUSION}

This pilot investigation has revealed that current and former student dental therapists and dental hygienists are enthusiastic in their support for the inclusion of community-based clinical teaching programmes in their educational and professional development. Most former and current student dental therapists and dental hygienists noted the positive effects of this form of training on their subsequent clinical careers. Further work is required to understand how learning in this environment helps develop suitable dental teams for the delivery of quality oral healthcare.

We gratefully acknowledge the assistance of Ms Annette Woodyatt for her administrative support.

1. Dyer T A, Robinson P G. Public awareness and social acceptability of dental therapists. Int J Dent Hyg 2009; 7: 108-114.

2. Ward P. The changing skill mix - experiences on the introduction of the dental therapist into general dental practice. Br Dent J 2006; 200: 193-197.

3. Ross M K, Ibbetson R J, Turner S. The acceptability of dually - qualified dental hygienist - therapists to general dental practitioners in South - East Scotland. Br Dent J 2007; 202: E8.

4. General Dental Council. Scope of practice. London: General Dental Council, 2009.

5. Gallagher J L, Wright D A. General dental practitioners' knowledge of and attitudes towards the employment of dental therapists in general practice. Br Dent J 2002; 193: 37-41.

6. Rowbotham J S, Godson J H, Williams S A, Csikar $\mathrm{J}$ I. Dental therapy in the United Kingdom: part 1. Developments in therapists' training and role. $\mathrm{Br}$ Dent J 2009; 207: 355-359.

7. Personal communication. General Dental Council's Registration Team. 9 April 2010.

8. Department of Health. NHS dentistry: options for change. London: Department of Health, 2002.

9. Evans C, Chestnutt I G, Chadwick B. The potential for delegation of clinical care in general dental practice. Br Dent J 2007; 203: 695-699.

10. Lynch C D, Ash P J, Chadwick B L, Treasure E T. Community-based clinical teaching. Br Dent J 2009; 207: 141

11. Skelton J, Mullins M R, Kaplan A L, West K P, Smith T A. University of Kentucky community-based field experience: program description. J Dent Educ 2001; 65: 1238-1242.

12. DeCastro J E, Bolger D, Feldman C A. Clinical competence of graduates of community-based and traditional curricula. J Dent Educ 2005; 69: 1324-1331.

13. Woronuk J I, Pinchbeck Y J, Walter M H. University of Alberta dental students' outreach clinical experience: an evaluation of the program. J Can Dent Assoc 2004; 70: 233-236.

14. Abuzar M A, Burrow M F, Morgan M. Development of a rural outplacement programme for dental undergraduates: students' perceptions. Eur J Dent Educ 2009; 13: 233-239.

15. Hunter M L, Chaudhry U. Paediatric dentistry in outreach settings: an essential part of undergraduate curricula? Eur J Dent Educ 2009; 13: 199-202.

16. Elkind $A$, Watts $C$, Qualtrough A et al. The use of outreach clinics for teaching undergraduate restorative dentistry. Br Dent J 2006; 203: 127-132.

17. Smith M, Lennon M A, Brook A H, Robinson P G. A randomised controlled trial of outreach placement's effect on dental students' clinical confidence. J Dent Educ 2006; 70: 566-570.

18. Craddock H L. Outreach teaching - the Leeds experience: reflections after one year. Br Dent J 2008; 204: 319-324.

19. Davies B R, Leung A N, Dunne S M. Perceptions of a simulated general dental practice facility - reported experiences from past students at the Maurice Wohl General Dental Practice Centre 2001 - 2008. Br Dent J 2009; 207: 371-376.

20. Lynch C D, Ash P J, Chadwick B L. Student perspectives and opinions on their experience at an undergraduate outreach dental teaching centre at Cardiff: a 5-year study. Eur J Dent Educ 2010; 14: 12-16.

21. Lynch C D, Ash P J, Chadwick B L, Hannigan A. The effect of community-based clinical teaching programmes on student confidence: a view from the United Kingdom. J Dent Educ 2010; 74: 510-516.

22. Lynch C D, Ash P J, Chadwick B L, Hannigan A. Evaluation of a UK community-based clinical teaching/ outreach programme by former dental students two and five years post-qualification. J Dent Educ 2010; 74: 1446-1152.

23. Csikar J I, Bradley S, Williams S A, Godson J H, Rowbotham J S. Dental therapy in the United Kingdom: part 4. Teamwork - is it working for dental therapists? Br Dent J 2009; 207: 529-536.

24. Gallagher J E, Wilson N H F. The future dental workforce? Br Dent J 2009; 206: 195-199.

25. Bartlett D, Preiskel A, Shah P, Ahmed A, Moazzez R. An audit of prosthodontics undertaken in general dental practice in the South East of England. $\mathrm{Br}$ Dent J 2009; 207: E15.

26. Patel P M, Lynch C D, Sloan A J, Gilmour A S M. Treatment planning for replacing missing teeth in UK general dental practice: current trends. J Oral Rehabil 2010; 37: 509-517.

27. Lynch C D, McConnell R J. Attitudes and use of rubber dam by lrish general dental practitioners. Int Endod J 2007; 40: 427-432.

28. General Dental Council. The first five years: the undergraduate dental curriculum. 3rd ed (interim). London: General Dental Council, 2008.

29. General Dental Council. Developing the dental team. 2nd ed (interim) 2009. London: General Dental Council, 2009.

30. Ross M K, Turner S, Ibbetson R J. The impact of teamworking on the knowledge and attitudes of final year dental students. Br Dent J 2009; 206: 163-167.

31. Blaxter L, Hughes $C$, Tight M. How to research, 3rd ed. Berkshire, England: Open University Press, 2006

32. Oppenheim A N. Questionnaire design, interviewing and attitude measurement. London: Continuum, 2003.

33. Bell J. Doing your research project: a guide for firsttime researchers in education, health and social science, 4th ed. Berkshire, England: Open University Press, 2005.

34. Tan R T, Burke F J T. Response rates to questionnaires mailed to dentists. A review of 77 publications. Int Dent J 1997: 47: 349-354.

35. Lynch C D, O'Byrne M T, McConnell R J, Neville K. Opinions of Irish dental practitioners on dental nurse training. J Ir Dent Assoc 2003; 49: 90-94.

36. Brand HS, Kuin D, Baart J A. A survey of local anaesthesia education in European dental schools. Eur J Dent Educ 2008; 12: 85-88. 